\title{
Cyclooxygenase-2 and hypoxia-regulated proteins are modulated by basic fibroblast growth factor in acute renal failure
}

\author{
Sandra Villanueva ${ }^{1}$, Pía Escobar ${ }^{1}$, Ioram Jacubovsky ${ }^{1}$, Carlos Irarrázabal' ${ }^{1}$ Juan E Carreño ${ }^{1}$, José M. Erpel², Carlos \\ Céspedes ${ }^{2}$, Alexis A. González², Carlos P. Vio² And Victoria Velarde ${ }^{2}$
}

${ }^{1}$ Laboratory of Integrative and Molecular Physiology, Universidad de los Andes, Santiago, Chile. ${ }^{2}$ Department of Physiology, Center for Aging and Regeneration, Pontificia Universidad Católica de Chile, Santiago, Chile.

\begin{abstract}
Acute renal failure (ARF) can be caused by injuries that induce tissue hypoxia, which in turn can trigger adaptive or inflammatory responses. We previously showed the participation of basic fibroblast growth factor (FGF-2) in renal repair. Based on this, the aim of this study was to analyze the effect of FGF-2 signaling pathway manipulation at hypoxia-induced protein levels, as well as in key proteins from the vasoactive systems of the kidney. We injected rat kidneys with FGF-2 recombinant protein (r-FGF) or FGF-2 receptor antisense oligonucleotide (FGFR2-ASO) after bilateral ischemia, and evaluated the presence of iNOS, EPO and HO-1, in representation of hypoxiainduced proteins, as well as COX-2, renin, kallikrein, and B2KR, in representation of the vasoactive systems of the kidney. A reduction in iNOS, HO-1, EPO, renin, kallikrein, B2KR, and in renal damage was observed in animals treated with r-FGF. The opposite effect was found with FGF-2 receptor down-regulation. In contrast, COX-2 protein levels were higher in kidneys treated with r-FGF and lower in those that received FGFR2-ASO, as compared to saline treated kidneys. These results suggest that the protective role of FGF-2 in the pathogenesis of ARF induced by $I / R$ is a complex process, through which a differential regulation of metabolic pathways takes place.
\end{abstract}

Key words: ARF, COX-2, FGF-2, kidney regeneration.

\section{INTRODUCTION}

Acute renal failure (ARF) is known to be associated with high mortality and morbidity (Schrier et al., 2004). ARF has an initiating phase characterized by organ dysfunction (Sutton et al., 2002), an extension phase marked by inflammatory responses (Molitoris and Sutton, 2004), and a resolution phase in which cellular repair typically occurs (Sutton et al., 2002).

Acute tubular necrosis (ATN) is a common cause of ARF (Esson and Schrier, 2002), and is observed in hypoxic conditions such as hemorrhagic shock or sepsis (Mehta, 2003). The transcriptional response to hypoxia can be adaptive or inflammatory (Taylor and Colgan, 1999). Adaptive responses are controlled through the nuclear accumulation of hypoxiainducible factor 1 alpha (HIF-1 $\alpha$ ), and by other proteins that support tissue survival that are controlled by HIF-1 $\alpha$ (Bunn and Poyton, 1996), such as erythropoietin (EPO), heme oxygenase-1 (HO-1) and inducible nitric oxide synthase (iNOS) (Ashley et al., 2002; Lee et al., 1997; Melillo et al., 1997; Noiri et al., 2001). Accordingly, the increased expression of these proteins may be linked to the resolution phase of ARF (Kirkby and Adin, 2006). We previously reported changes in the expression of EPO and $\mathrm{HO}-1$, using an experimental approach of renal ischemia/reperfusion (I/R) as a model of ATN (Villanueva et al., 2007).

A healthy kidney produces vasoactive substances through the activation of the renin-angiotensin system (RAS), and the kallikrein-kinin system (KKS). These vasoactive systems not only participate in maintaining renal blood flow and adequate glomerular filtration rates, but are also involved in renal development (Shen and El-Dahr, 2006). In addition, eicosanoids, the products of cyclooxygenases (COX type 1 and 2), exert physiological activity in the kidney and other organs, thus playing an important role in the regeneration of damaged tissue, as reported for endothelial (Eligini et al., 2009), gastric mucosal (Brzozowski et al., 2000; Mizuno et al., 1997), skin (Hamamoto et al., 2009), skeletal muscle (Bondesen et al., 2004), corneal endothelial (Jumblatt and Willer, 1996), lung (Fukunaga et al., 2005), colon (Reuter et al., 1996) and glomerular mesangial cells (Ishaque et al., 2003). Although COX-2 has been postulated to cause adverse events in the kidney, including ARF (Braden et al., 2004, Seibert et al., 1994), this enzyme has a physiological role in the normal adult kidney (Vio et al., 1997; Vio et al., 2001; Leon et al., 2001) and is necessary for normal kidney development (Vio et al., 1999). In experimental I/R we have observed alterations in the KKS and in the RAS. The observed increase in renin and decrease in kallikrein and COX-2 protein levels suggest a differential regulation of these proteins during ischemic damage (Villanueva et al., 2007). Considering that these enzymes are important in renal development, they could also be part of the regenerative phase described in ARF.

Fibroblast growth factor (FGF) has been suggested to be a renal protector in I/R (Cuevas et al., 1999). Furthermore, basicFGF (FGF-2) has been postulated to be involved in epithelialmesenchymal transition and early tubulogenesis (Perantoni et al., 1995). Using a recombinant protein (r-FGF), we have observed a correlation between the increase of FGF-2 and the increase of some proteins during ATN recovery, which are known to be implicated in kidney development (Villanueva et al., 2006a; Villanueva et al., 2006b, Villanueva et al., 2008). Nevertheless, the complete regenerative responses induced by FGF-2 in experimental I/R cannot be understood based solely on the induction of these proteins. Several publications have 
also shown an FGF effect on proteins regulated by hypoxia in different tissues (Akiba et al., 1997; Neuvians et al., 2004; Schmerer et al., 2006).

In light of this evidence, we hypothesized that FGF modulation of the protein levels induced by hypoxia and key proteins from the vasoactive systems of the kidney could contribute to the resolution phase of ARF. To this purpose, we manipulated FGF-2 levels in an experimental model of $I / R$, and studied the relative abundance of iNOS, EPO and HO- 1 in representation of hypoxia-induced proteins, as well as levels of COX-2, renin, kallikrein, and the B2 kinin receptor (B2KR) in representation of the vasoactive systems of the kidney.

\section{MATERIALS AND METHODS}

Animals

Adult male Sprague-Dawley rats (220 to $250 \mathrm{~g}$, $\mathrm{n}=7$ for each I/R group: $24 \mathrm{~h}, 48 \mathrm{~h}, 72 \mathrm{~h}$ and $96 \mathrm{~h}$ ) were housed in a $12 \mathrm{~h}$ light/ dark cycle. Animals were weighed at the time of bilateral ischemic injury initiation and after completion of experiments. Animals had free access to food and water, and were kept at the animal care facilities of the Universidad Católica de Chile. All experimental procedures were in accordance with institutional and international standards for the humane care and use of laboratory animals (Animal Welfare Assurance Publication A5427-01, Office for Protection from Research Risks, Division of Animal Welfare, National Institutes of Health).

\section{Renal ischemia/reperfusion injury}

An established model was performed of renal I/R injury that resembles structural and functional consequences of renal ischemia, including apoptotic tubular epithelial cells (Perantoni et al., 1995). Animals were anesthetized with ketamine: xylazine $(25: 2.5 \mathrm{mg} / \mathrm{kg}$, ip), maintaining body temperature at $37^{\circ} \mathrm{C}$. Both kidneys were exposed by a flank incision and both renal arteries were occluded with a non-traumatic vascular clamp for 30 minutes. Then, while clamps were in position, the left kidney was injected in the parenchymal medullary area with $200 \mu \mathrm{l}$ of r-FGF $(30 \mathrm{mg}$ / $\mathrm{kg}$ ) (Villanueva et al., 2008; Unger et al., 2000) or FGFR2-ASO (112 $\mu \mathrm{g} / \mathrm{kg})$ (Villanueva et al., 2006b; Carstens et al., 2000) (preliminary experiments using methylene blue dye or Bouin's solution demonstrated that the volume used allowed extensive diffusion over the tissue); the right kidney was injected with the same volume of saline $\mathrm{NaCl}, 0.9 \%$ (S), used as a vehicle for the oligonucleotides, and also used for control purposes. After injection clamps were removed, renal blood flow was reestablished and both incisions were sutured. Rats were allowed to recover in a room at warm temperature levels. 24, 48, 72 and 96 hours after reperfusion, both kidneys were removed and the animals were sacrificed by exsanguination under heavy anesthesia (ketamine: xylazine). The kidneys were then processed for immunohistochemistry and Western blotting.

Tissue processing and immunohistochemical analysis

Tissue processing for immunohistochemical studies in paraplast-embedded sections was carried out according to methods previously described (Vio et al., 1999; Vio et al., 2001). Immunolocalization studies were performed using an indirect immunoperoxidase technique (Villanueva et al., 2006a). Briefly, tissue sections were dewaxed, rehydrated, rinsed in $0.05 \mathrm{M}$ tris-phosphate-saline (TPS) buffer ( $\mathrm{pH}$ 7.6) and incubated with the primary antibody overnight at $22^{\circ} \mathrm{C}$. Sections were subsequently washed, followed by 30 minutes of incubation with the corresponding secondary antibody and with the peroxidase-antiperoxidase (PAP) complex. Immunoreactive sites were revealed using $0.1 \%$ of 3,3'-diaminobenzidine (wt/vol) and $0.03 \%$ ( $\mathrm{vol} / \mathrm{vol}$ ) of hydrogen peroxide solution.

Antibodies and chemicals

The following primary antibodies were used: monoclonal antibodies against macrophages (clone ED-1, Biosource, Camarillo, CA), monoclonal antibodies against a-smooth muscle actin ( $\alpha$-SMA: clone 1A4, Sigma Aldrich Co., St. Louis, $\mathrm{MO}$ ), monoclonal antibodies against iNOS (Transduction Labs., Lexington, KI), goat polyclonal antibodies against COX-2 (Cayman Chemical Company, Ann Arbor, MI), goat polyclonal antibodies against EPO (Santa Cruz Biotechnology, Inc., Santa Cruz, CA), goat polyclonal antibodies against HO-1 (StressGen Biotechnologies Corp., Victoria, Canada), and rabbit monoclonal against FGFR2 (clone EPR5180, Epitomics, Inc. Burlingame, CA). Rabbit polyclonal antibodies against renin, $\mathrm{B} 2 \mathrm{KR}$ and kallikrein were prepared as described previously (Velarde et al., 1995).

Secondary antibodies and the corresponding PAP complexes were purchased from MP Biomedicals, Inc. (Aurora, $\mathrm{OH})$. Triton X-100, 3,3'-diaminobenzidine, carrageenan, tris$\mathrm{HCl}$, hydrogen peroxide, phosphate salts, and other chemicals were purchased from Sigma Aldrich Co. (St. Louis, MO).

\section{Western-blotting}

For Western-blotting experiments, longitudinal sections from kidneys including the inner and outer medulla (approximately $1 \mathrm{~mm}$ thick) were homogenized with an Ultra-Turrax homogenizer in PBS 1X buffer containing $0.05 \mathrm{M}$ of EDTA and a protease inhibitor cocktail (Pierce, Rockford, IL). The protein concentration was determined by the method of Bradford (Bio-Rad, Richmond, CA). Western blotting was performed as previously described (Villanueva et al., 2006a). Briefly, sixty micrograms of protein were mixed with an equal volume of SDS-PAGE sample buffer (100 mM tris- $\mathrm{HCl}, \mathrm{pH} 6.8,200 \mathrm{mM}$ dithiothreitol, $4 \%$ SDS, $0.2 \%$ bromophenol blue, $20 \%$ glycerol). Proteins were separated on $12 \%$ SDS-polyacrylamide gels and transferred to nitrocellulose membranes. Blocking was carried out by incubation in blocking solution ( $8 \%$ nonfat dry milk in tris-buffered saline- $0.1 \%$ tween) for 2 hours at room temperature. After blocking, membranes were probed with the corresponding primary antibody for 18 hours at $4^{\circ} \mathrm{C}$, washed with tris-buffered saline-tween, and incubated with the appropriate horseradish peroxidase (HRP)-conjugated secondary antibody for 1 hour at room temperature. Proteins were detected by using enhanced chemiluminescence techniques (Pierce, Thermo Scientific, Rockford, IL).

Subsequently, blots were scanned and densitometric analysis was performed by using the public domain NIH Image program v1.61 (US National Institutes of Health, http:/ / 
rsb.info.nih.gov/nih-image). The expression of $\alpha$-tubulin was used to correct variation in sample loading.

Determination of tissue damage and immunohistochemical quantification

Tissue damage was evaluated through periodic acidSchiff (PAS) staining. Immunolocalization of ED-1 and interstitial $\alpha$-SMA were used as tissue damage markers. The immunoreactive area in each field (whole kidney sections) was determined by image analysis using Simple PCI software (Compix). Total immunostained (brown) cells were averaged and expressed as the mean absolute values or the mean percentage of stained cell area per field, as previously described (Villanueva et al., 2006a) with minor modifications.

\section{Statistical Analysis}

The differences were assessed with the Mann-Whitney nonparametric test for pair-wise comparisons, when overall significance was detected. The significance level was defined at $P<0.05$. Protein densitometry values are presented as mean \pm SD. All values are represented by Arbitrary Units (AU).

\section{RESULTS}

\section{Determination of tissue damage}

According to our hypothesis, if FGF-2 modulates the levels of proteins involved in the different phases of ARF, the reduction of FGF-2, or its signaling should therefore alter the levels of such proteins. With this idea in mind, we injected the kidneys with FGF receptor type 2 (FGFR2) antisense oligonucleotide (ASO). To confirm that the antisense oligonucleotide reduced the expression of the receptor, kidneys injected with ASO (Fig. 1A) and control kidneys injected with a scrambled oligonucleotide (Fig. 1B) were stained against this receptor. As shown in Fig. 1, immunostaining for the FGF receptor was not observed when kidneys were injected with the ASO, thus confirming the effectiveness of the antisense oligonucleotide on the expression of the receptor.

Renal functional damage produced by $I / R$ was assessed by serum creatinine levels. Rats subjected to $I / R$, and injected with saline had creatinine levels of $0.6 \pm 0.1 \mathrm{mg} / \mathrm{dL}$ two days after injection. Creatinine levels were $0.40 \pm 0.02 \mathrm{mg} / \mathrm{dL}$ in animals subjected to $I / R$ and injected with r-FGF, whereas such levels were $0.9 \pm 0.2 \mathrm{mg} / \mathrm{dL}(P<0.05)$ in rats subjected to $\mathrm{I} / \mathrm{R}$ and injected with FGFR2-ASO.

PAS staining of sections from kidneys injected with saline 48 hours after I/R showed alterations in morphology, which is consistent with ATN (Fig. 2B) as compared to sham operated animals (Fig. 2A). These alterations were characterized by flattening of the brush border epithelia and a high percentage of proximal tubule cells undergoing mitosis. However, detection of such alterations did not occur 96 hours after $\mathrm{I} / \mathrm{R}$ (data not shown), in accordance with previous results (Villanueva et al., 2006b). Kidneys treated with r-FGF showed a morphology closer to normal at 48 hours after I/R (Fig. 2C), compared to those injected with saline (Fig. 2B). Nevertheless, an important level of mitosis was maintained. Kidneys treated with FGFR2-ASO showed altered morphology, with an increase in the damaged area as mentioned above. These alterations in renal structure were observed 24 hours after I/R and were maintained for 96 hours (Fig. 2D).

Regarding renal damage markers, an increased number of interstitial macrophages (ED-1) and interstitial myofibroblasts ( $\alpha$-SMA) were observed 48 hours after I/R in kidneys injected with saline (ED-1: $238 \mu \mathrm{m}^{2}$ and $\alpha$-SMA: $22,103 \mu \mathrm{m}^{2}$ ) (Fig. $2 \mathrm{~F}, \mathrm{~J}$ ), when compared to sham operated animals (Fig. 2E, I), similar to what was reported previously (Villanueva et al., 2006b). In contrast, r-FGF treated rats showed lower numbers of both markers (ED-1: $180 \mu \mathrm{m}^{2}$ and $\alpha$-SMA: 4,392 $\mu \mathrm{m}^{2}$ ) at the same period of time, without apparent morphological alterations (Fig. 2G, K). Kidneys injected with FGFR2-ASO showed an increased number of macrophages (ED-1: $650 \mu \mathrm{m}^{2}$ ) and interstitial $\alpha$-SMA $\left(47,369 \mu \mathrm{m}^{2}\right)$, which was maintained up to 96 hours after I/R (Fig. 2H, L). This histological data was well correlated with the creatinine levels mentioned above.

iNOS, HO-1 and EPO levels in I/R kidneys treated with $r$-FGF or FGFR2-ASO

To understand the mechanism associated with experimental $I / R$ and the putative effect of FGF-2, we analyzed three stress proteins induced by hypoxia, namely iNOS, HO-1
Anti-sense oligo

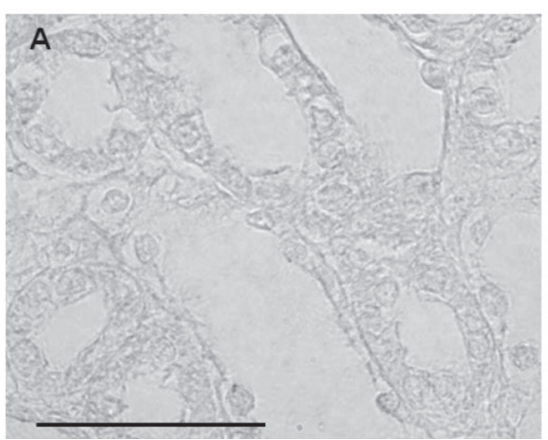

Scramble oligo

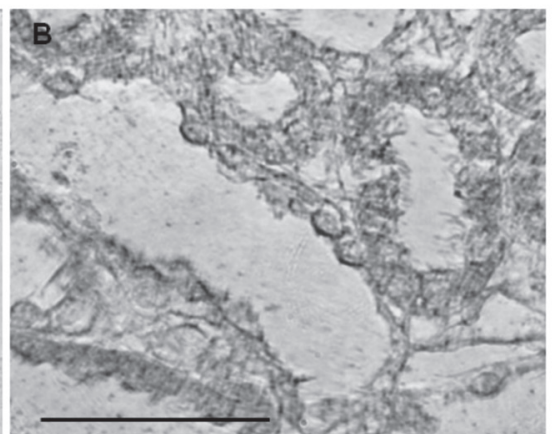

Figure 1: ASO effect on FGFR2 expression in medullary renal tubules. IHQ was performed on kidneys samples obtained 48 hours after injection with (A) an FGF receptor type 2 antisense oligonucleotide (FGFR2-ASO), or (B) a scrambled oligonucleotide (SO), ( $\mathrm{n}=5$ for each group). An important reduction in bFGFR2 staining was observed in kidneys treated with ASO, compared to kidneys injected with scrambled oligonucleotides. Staining was observed in the entire cell area. Scale bar $=50 \mu \mathrm{m}$. 
and EPO, and compared the relative abundance of these proteins when kidneys were injected with r-FGF or FGFR2ASO. When kidneys were injected with saline, the levels of the three proteins were higher when observed 24 hours after I/R. However, as can be seen in Fig. 3, the levels of the three proteins decreased at 48 hours compared to their levels at 24 hours (iNOS: $185 \pm 16 \mathrm{AU}$ at $24 \mathrm{~h} \mathrm{v} / \mathrm{s} 82 \pm 15 \mathrm{AU}$ at $48 \mathrm{~h}$; HO-1: $126 \pm 34 \mathrm{AU}$ at $24 \mathrm{~h} \mathrm{v} / \mathrm{s} 15 \pm 8 \mathrm{AU}$ at $48 \mathrm{~h}$; and EPO: $125 \pm 26 \mathrm{AU}$ at $24 \mathrm{~h} \mathrm{v} / \mathrm{s} 77 \pm 9 \mathrm{AU}$ at $48 \mathrm{~h}$; $P<0.05$ ) (Fig. 3, circles A,B \& C). Nevertheless, an important reduction in the levels of these markers was observed at 24 hours in kidneys treated with r-FGF compared to saline injected kidneys (iNOS: $37 \pm 2 \mathrm{AU}$; HO-1: $15 \pm 4$ AU and EPO: $88 \pm 5$ AU; $P<0.05$ ) (Fig. 3, squares). Furthermore, a significant increase in these proteins was maintained in kidneys treated with FGFR2-ASO for at least 96 hours after experimental I/R (iNOS: $214 \pm 18$ AU; HO-1: 126 \pm $28 \mathrm{AU}$ and EPO $165 \pm 24 \mathrm{AU}$ at $96 \mathrm{~h} ; \mathrm{P}<0.05)$ (Fig. 3, triangles). Since two bands were observed for HO-1 and EPO, only the band closer to the molecular weight described for each of these proteins was used for densitometry.

The protein distribution of iNOS, HO- 1 and EPO was analyzed by immunohistochemistry. At $48 \mathrm{~h}$ after I/R, iNOS was observed in collecting ducts localized in the outer medulla (Fig. 4, A, B \& C), and HO-1 was localized in the cortical area, mainly in interstitial cells. iNOS was still observed in the outer medulla in r-FGF treated kidneys, but was limited to certain tubules, while HO-1 was mainly localized in some tubular cells, possibly due to a treatment effect (Fig. 4, D, E \& F). In the case of FGFR2-ASO treated rats, immunostaining for iNOS was still observed in all tubular segments, while HO-1 was again observed in the interstitium. Accordingly, when the immunostaining was quantified, kidneys from animals treated with r-FGF showed a lower staining for iNOS and HO-1, 48 hours after experimental I/R (iNOS: 6,232 $\mu^{2}$ and HO-1: 433 $\mu \mathrm{m}^{2}$ ) (Fig. 4, B \& E), when compared to the group treated with saline (iNOS: 13,645 $\mu \mathrm{m}^{2}$ and HO-1: $966 \mu \mathrm{m}^{2}$ ) (Fig. 4, A \& D). Moreover, this reduction was still observed 96 hours after I/R (data not shown). In contrast, kidneys treated with FGFR2-ASO showed an increase in the staining for both proteins 48 hours after I/R (iNOS: 20,469 $\mu \mathrm{m}^{2}$ and HO-1: $948 \mu \mathrm{m}^{2}$ ) (Fig 4, C \& F), which was maintained for 96 hours after I/R, compared to the group treated with saline (Fig. 4, A \& D). Immunostaining for EPO was localized mainly in a few cells of the kidney cortex in animals submitted to $I / R$ and injected with saline after 48 hours (Fig. 4, G). The staining was higher in animals treated with FGFR2-ASO $\left(2,124 \mu \mathrm{m}^{2}\right)$ (Fig. 4, I), compared to animals treated with r-FGF $\left(535 \mu \mathrm{m}^{2}\right)$ (Fig. 4, H). The distribution was mainly peritubular, close to proximal tubules and loops of Henle. However, in the r-FGF group it was also localized in tubular cells, probably due to a treatment effect.

Renal levels of vasoactive system components are regulated by the FGF-2 pathway

Normal kidney function is due to the proper balance between the KKS and the RAS (Schmaier, 2003). In addition, these

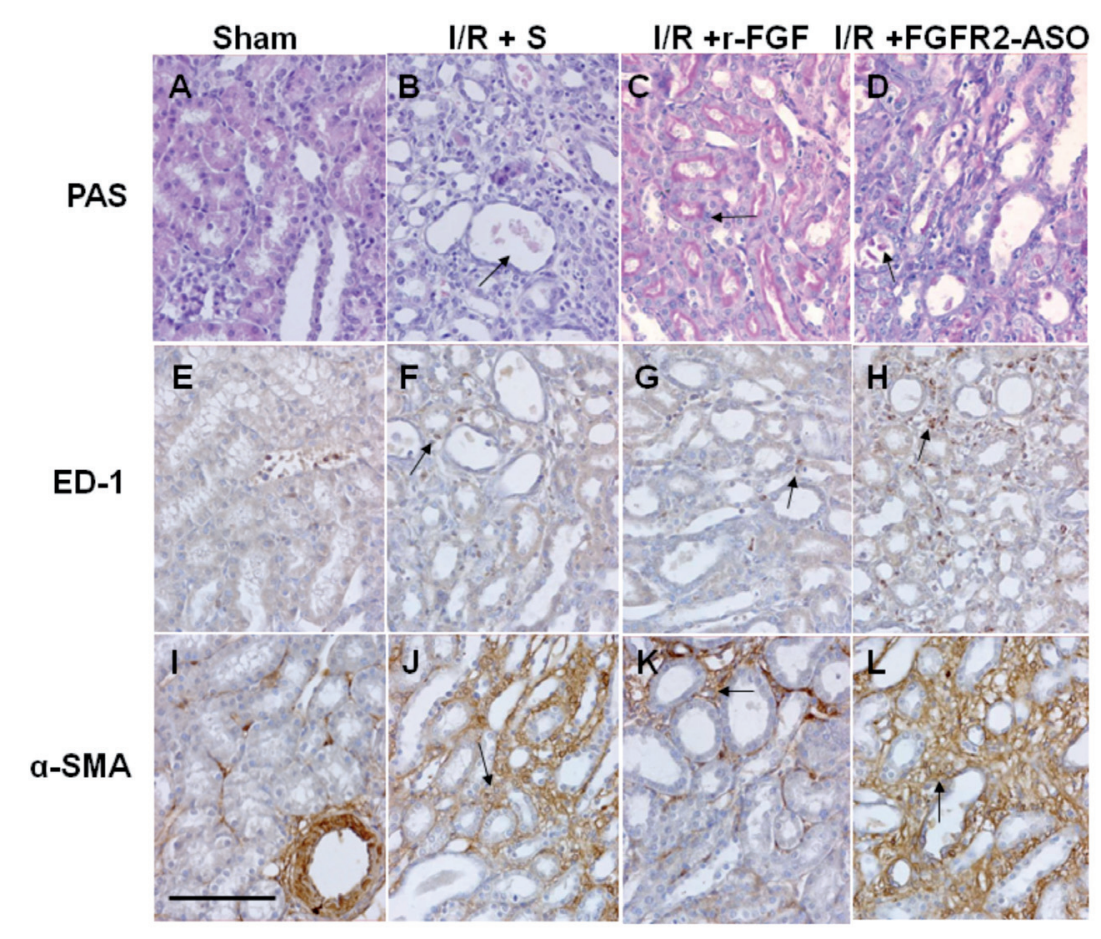

Figure 2: Evidence of histological renal damage in hypoxic kidney induced by $\mathbf{I} \mathbf{R}$ and treated with r-FGF or FGFR2-ASO. Immunohistochemistry was performed on kidney samples from sham operated animals (A,E \& I), or obtained 48 hours after I/R and saline (S) injection (B,F \& J) or FGF-2 recombinant protein (r-FGF) (C,G \& $\mathbf{K})$, and at 96 hours after I/R in kidneys injected with FGF-2 receptor 2 antisense oligonucleotides (FGFR2-ASO) (D,H \& L) ( $n=7$ for each group). Histological damage was evaluated by PAS staining (A,B,C \& D). Brush border, epithelial flattening and mitosis are shown. Induction of renal damage markers such as ED-1 (E,F,G \& H) as a measurement of macrophages, or $\alpha$-SMA $(\mathbf{I}, \mathbf{J}, \mathbf{K} \& \mathbf{L})$ as a measurement of myofibroblasts, are shown. Scale bar=100 $\mu \mathrm{m}$. The arrows in $\mathrm{F}, \mathrm{G}, \mathrm{H}, \mathrm{J}, \mathrm{K}$, and $\mathrm{L}$ show one area where the markers are localized. 
systems are involved in renal development and maturation (Shen and El-Dahr, 2006). We evaluated the effect of FGF in the distribution and levels of certain components of these systems in kidneys after I/R (Fig. 5 and 6). First, we analyzed renin expression in the three conditions described above: saline, r-FGF and FGFR2-ASO. Kidneys treated with r-FGF showed an important reduction in renin levels at 24 hours compared to the saline group. This low level was maintained at 96 hours after $I / R$, which was when the renin levels in the saline group also decreased to a similar level $(24 \pm 3$ AU at 24 hours v/s 23 $\pm 3 \mathrm{AU}$ at 96 hours; $P<0.05$ ) (Fig. 5, A). Kidneys treated with FGFR2-ASO showed an increase in renin levels at all times analyzed after I/R $(182 \pm 16 \mathrm{AU}$ at 24 hours and $170 \pm 36 \mathrm{AU}$ at 96 hours; $P<0.05$ ) (Fig. 5, A). We previously demonstrated that kallikrein levels can be modulated after I/R (Villanueva et al., 2007). In the present study, we found that kallikrein levels were low at all analyzed times in kidneys treated with r-FGF, compared to the saline condition $(46 \pm 7 \mathrm{AU} \mathrm{v} / \mathrm{s} 76 \pm 5 \mathrm{AU}$ at

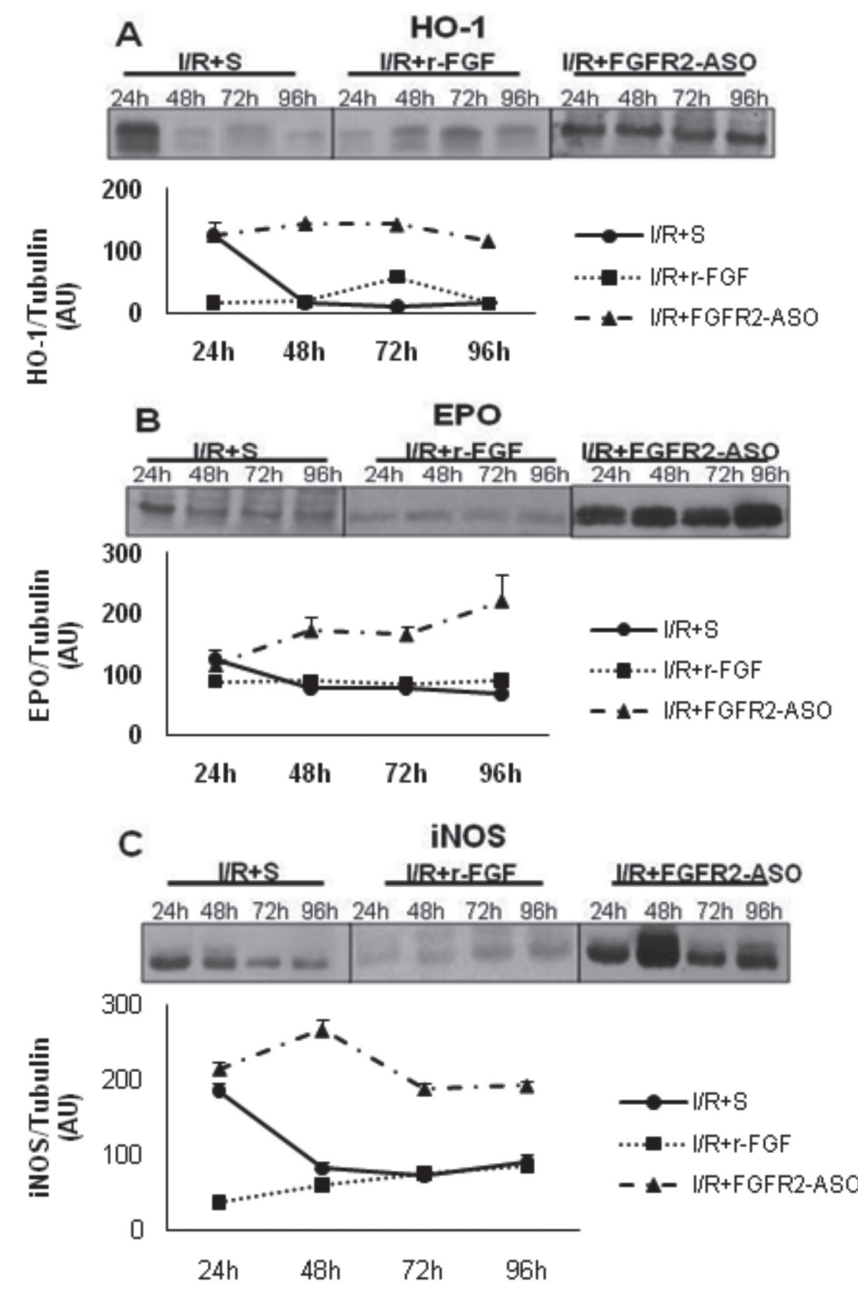

Figure 3: FGFR2-ASO and r-FGF effects on HO-1, EPO and i-NOS response in $\mathbf{I} / \mathbf{R}$-induced ARF. Proteins induced by hypoxia (A)HO-1, (B)EPO and (C)i-NOS were analyzed at 24, 48, 72 and 96 hours after a 30 min ischemia in kidneys injected with saline (circles), r-FGF (squares) or FGFR2-ASO (triangles). $n=7$ for each group. ${ }^{*}=P<0.05$ compared to saline at the same point in time.
24 hours) (Fig. 5, B). In contrast, kidneys treated with FGFR2ASO showed an increase in kallikrein levels 24 hours after I/R, which was maintained at all analyzed times $(115 \pm 13$ AU at 24 hours; $P<0.05$ ) (Fig. 5, B).

Another important KKS protein is the B2 kinin receptor (B2KR). In the case of kidneys treated with r-FGF, B2KR levels decreased at all evaluated times when compared to the saline group (27 $\pm 5 \mathrm{AU} \mathrm{v} / \mathrm{s} 149 \pm 5 \mathrm{AU}$ at 24 hours; $P<0.05$ ) (Fig. $5, \mathrm{C})$. In contrast, kidneys treated with FGFR2-ASO showed higher B2KR levels at all the analyzed times in contrast to the saline group (172 \pm 10 AU at 24 hours $P<0.05)$ (Fig. 5, C).

Immunostaining for renin, kallikrein and B2KR observed at 48 hours after treatment showed similar results to those observed by Western blot, that is, immunoreactivity in the r-FGF group decreased in cell number and in intensity (renin: $43 \mu \mathrm{m}^{2}$, kallikrein: $136 \mu \mathrm{m}^{2}$ and B2KR: $117 \mu \mathrm{m}^{2}$ ) (Fig. 6, E-G), compared to saline group (renin: $50 \mu \mathrm{m}^{2}$, kallikrein: $345 \mu \mathrm{m}^{2}$ and B2KR: $345 \mu \mathrm{m}^{2}$ ) (Fig. 6, A-C). In contrast, the kidneys treated with FGFR2-ASO showed increased immunoreactivity for renin, kallikrein and B2KR compared to the saline group (renin: $151 \mu \mathrm{m}^{2}$, kallikrein: $371 \mu \mathrm{m}^{2}$ and B2KR: $177 \mu \mathrm{m}^{2}$ ) (Fig. 6, I-K).

Kidneys submitted to I/R and injected with saline solution had almost undetectable COX-2 protein levels when measured by Western blot at 24,48 and 96 hours after I/R, with an increase at 72 hours after reperfusion (Villanueva et al., 2007). In contrast, kidneys treated with r-FGF showed an increased expression of COX-2 24 hours after I/R, which was maintained at all evaluation times $(126 \pm 35 \mathrm{AU}$ at 24 hours; $P<0.05)$ (Fig. 4, D). Conversely, COX-2 was not detectable by Western blot at any evaluation time in kidneys treated with FGFR2-ASO, (Fig. 5, D). In addition, IHC revealed that kidneys injected with r-FGF had an increased COX-2 immunoreactivity 48 hours after I/R $\left(118 \mu \mathrm{m}^{2}\right)$ (Fig. 6, H), whereas kidneys treated with FGFR2-ASO showed a decreased COX-2 staining $\left(14 \mu \mathrm{m}^{2}\right)$ (Fig. 6, L) when compared to control saline kidneys $\left(54 \mu \mathrm{m}^{2}\right)$ (Fig. 6, D).

As expected, COX-2 and B2KR were mainly observed in thick ascending limbs (Vio et al., 1999; Vio et al., 2001), renin was present in the afferent arteriole, and kallikrein was located in connecting tubule cells in the kidney cortex. The treatments with FGFR2-ASO or r-FGF did not modify the localization of these proteins.

\section{DISCUSSION}

ARF induced by ischemia is a reversible pathological condition, whose recovery is characterized by the restoration of the renal tubular system (Villanueva et al., 2006a). However, there are persistent post-ischemic alterations in renal function that can lead to permanent failures in urinary concentrating ability, associated with enduring vascular damage. One particular protein that has been observed to be altered, even several weeks after I/R, is Kallikrein (Basile et al., 2005).

We recently reported that FGF-2 prevents renal damage and stimulates kidney regeneration in an adult kidney $\mathrm{I} / \mathrm{R}$ model, through the induction of proteins involved in embryonic kidney development (Villanueva et al., 2008). In addition, recent studies performed in different tissues (esophagus, gastric mucosa, corpus luteum and red blood cells), have shown an important interaction between FGF-2 and the vasoactive renal systems, or FGF-2 and stress proteins 


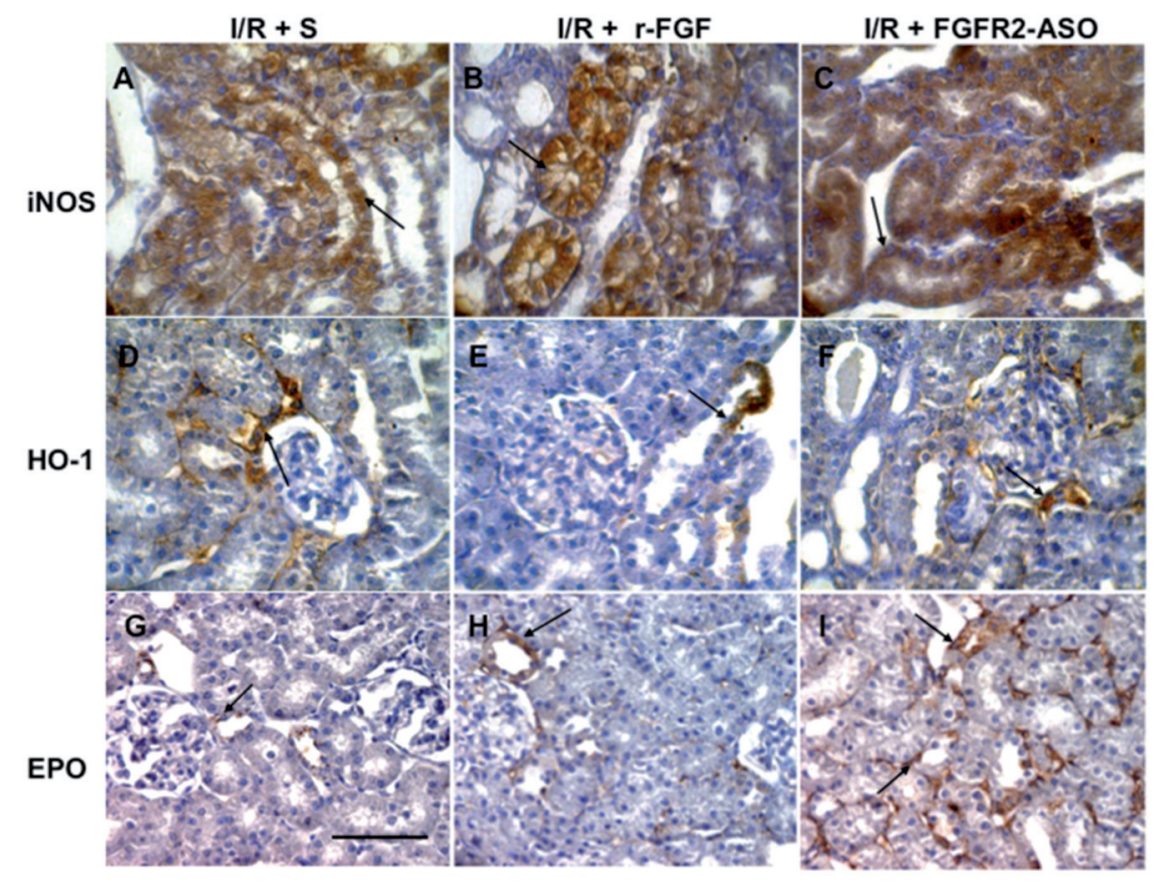

Figure 4: Immunolocalization of proteins that respond to hypoxia in I/R-induced ARF. Staining for iNOS (A,B \& C), HO-1 (D,E \& F) and EPO (G,H \& I) was observed 48 hours after I/R in kidneys injected with saline (A,D \& G), r-FGF (B,E \& H) or FGFR2-ASO (C,F \& I) (n=7 for each group). Scale bar $=100 \mu \mathrm{m}$. The arrows indicate representative immunostained (brown) areas.

A UR+S $\quad \begin{gathered}\text { RENIN } \\ \text { UR+r-FGF }\end{gathered}$ \begin{tabular}{|l|l|l|l|}
\hline $24 \mathrm{~h} 48 \mathrm{~h} 72 \mathrm{~h} 96 \mathrm{~h} 24 \mathrm{~h} 48 \mathrm{~h} 72 \mathrm{~h} 96 \mathrm{~h}$ 24h 48h $72 \mathrm{~h} \quad 96 \mathrm{~h}$ \\
\hline- & & - \\
\hline
\end{tabular}

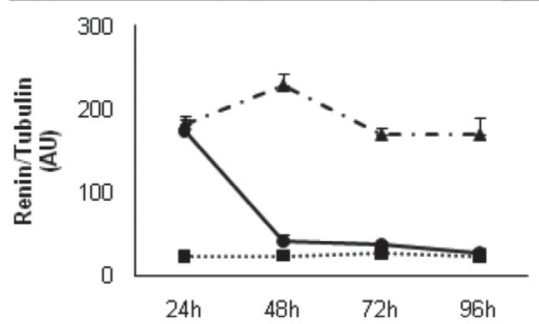

C
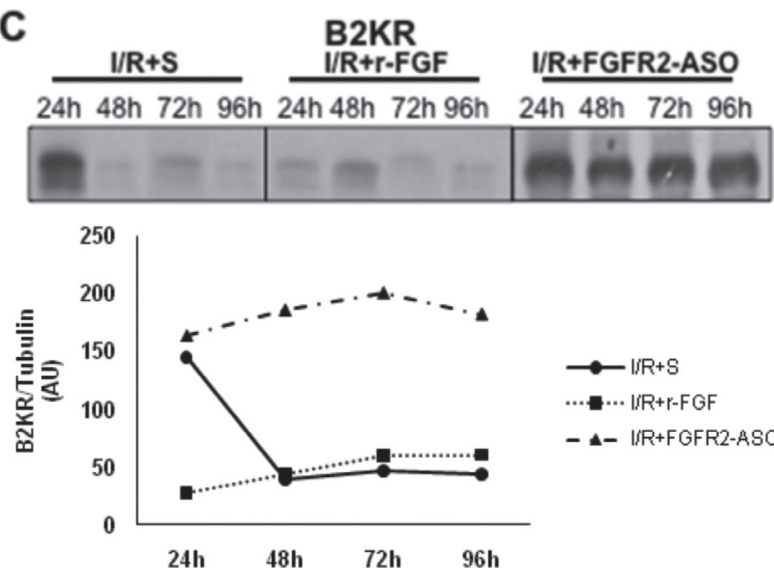

$\longrightarrow \mid S R+S$

- $\Delta-$ ISR+FGFR2-ASO

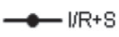

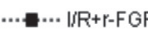

- A- IRR+FGFR2-ASO

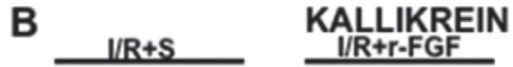
IR+r-FGF

IIR+FGFR2-ASO

24h 48h 72h 96h 24h 48h 72h 96h 24h 48h 72h 96h
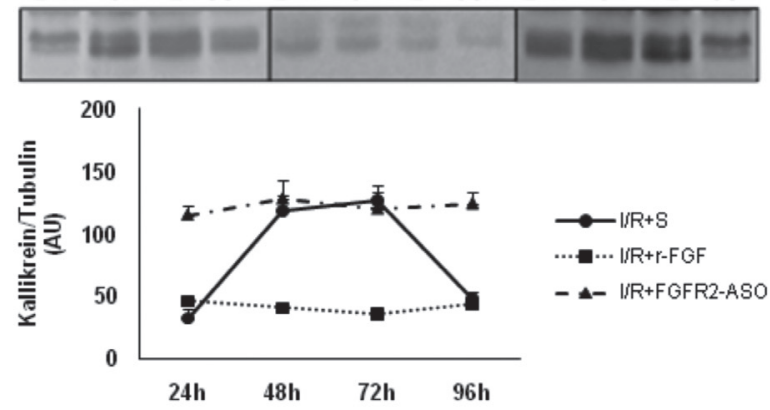

D
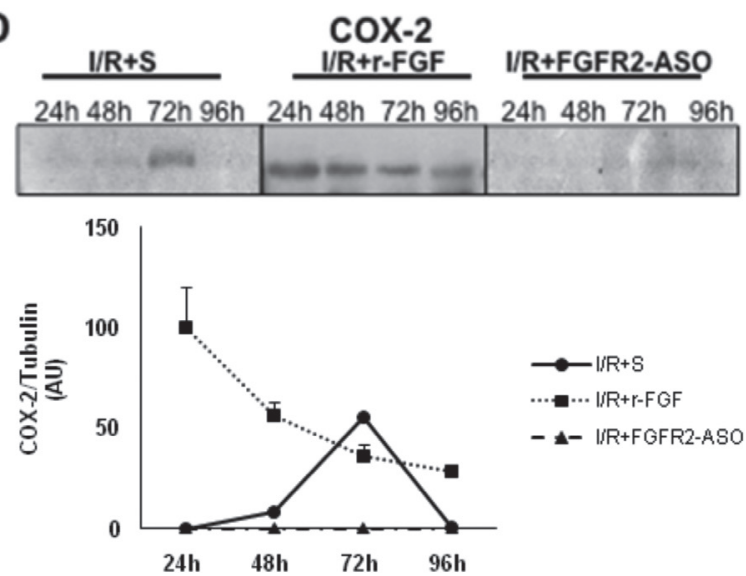

Figure 5: Immunoblot for vasoactive proteins in by I/R-induced ARF. Vasoactive proteins: renin (A), kallikrein (B), B2KR (C) and COX-2 (D), were analyzed at 24, 48, 72 and 96 hours after 30 min of ischemia in kidneys injected with saline (circles), r-FGF (squares) or FGFR2-ASO (triangles). ( $\mathrm{n}=7$ for each group). ${ }^{*}=P<0.05$ compared to saline at each time point. 
induced by hypoxia (Schmerer et al., 2006; Unger et al., 2000; Carstens et al., 2000; Baguma-Nibasheka et al., 2007;Martins et al., 2008). This raises the possibility that FGF-2 may have a double role in kidney repair, by increasing the expression of repairing proteins, and by modulating the vasoactive systems of the kidney as well as the proteins related to the hypoxic stress response. In this study we performed complementary experiments to evaluate the direct effects of FGF-2 on the regulation of the components of these vasoactive systems and stress-related proteins induced by hypoxia, as well as their participation in renal damage and their involvement in persistent alterations.

FGFs mediate their biological effects by binding to, and activating receptors with tyrosine kinase activity. This interaction results in a series of molecular events that culminate in biological responses such as mitosis, differentiation or migration (Friesel and Maciag, 1999). In this regard, FGFR2 is localized throughout the whole cell and, as observed in some cases, staining up to the apical membrane, mainly in tubular segments of the inner stripe of the outer medulla, which is similar to what has been observed by other researchers (Cancilla et al., 2001). It can be speculated that the growth factor reaches its receptor from the blood vessels in normal conditions, but it can also reach the receptor through the tubular lumen when the filtration barrier is damaged.

We analyzed three stress proteins regulated by hypoxia (HO-1, EPO, and iNOS), and also proteins that are not only involved in urine concentration and blood pressure regulation, but in kidney development as well (B2KR, kallikrein, renin and COX-2). The major findings of this study were the significant decreases of most of these proteins in kidneys treated with r-FGF. To explain these results, we could speculate that FGF-2 is directly inhibiting the overexpression of these proteins, or that the effect of FGF-2 is indirect, probably mediated by HIF$1 \alpha$ or other transcription factors that are regulated by FGF- 2 . This pattern was the opposite for COX-2 proteins, since they increased in the r-FGF group. This result suggests that COX2 might be regulated by a different mechanism, as discussed later.

Although three $\mathrm{HO}$ isoforms have been reported, only the inducible isoform HO-1 is expressed in renal tissue (Yang et al., 2004). HO-1 induction occurs as an adaptive and beneficial response to several injury processes, including oxidative injuries (Morimoto et al., 2001), rhabdomyolysis (Carstens et al., 2000), cisplatin nephrotoxicity and ARF (Shimizu et al., 2000). This may be explained by the generation of products from heme degradation, iron, carbon monoxide, biliverdin and bilirubin, which exert important antioxidant, antiinflammatory, and cytoprotective functions (Kirkby and Adin, 2006). We found increased levels of HO-1 in kidneys with high damage induced by FGFR2-ASO. This could be explained by a compensatory mechanism against maladaptive responses stimulated by hypoxia. In addition, the low levels of HO-1 observed even at 24 hours after I/R, when r-FGF was injected, could be explained by the anticipation of HO-1 level reduction, as compared to the effect under the saline injection condition.

EPO is a protein involved in renal erythropoiesis, and as such, it is regulated by hypoxia. EPO has protective effects on retina and renal tubular cells; in the specific context of ARF (Sharples et al., 2005), EPO exerts its action through the activation of Janus kinase 2, Akt, and multiple targets with antiapoptotic effects (Sharples et al., 2004). In addition, FGF has been reported to inhibit EPO-induced erythropoiesis (Schmerer et al., 2006; Kreja et al., 1993). It is possible that the observed EPO induction in ischemic kidneys treated with FGFR2-ASO could be related to the molecular machinery

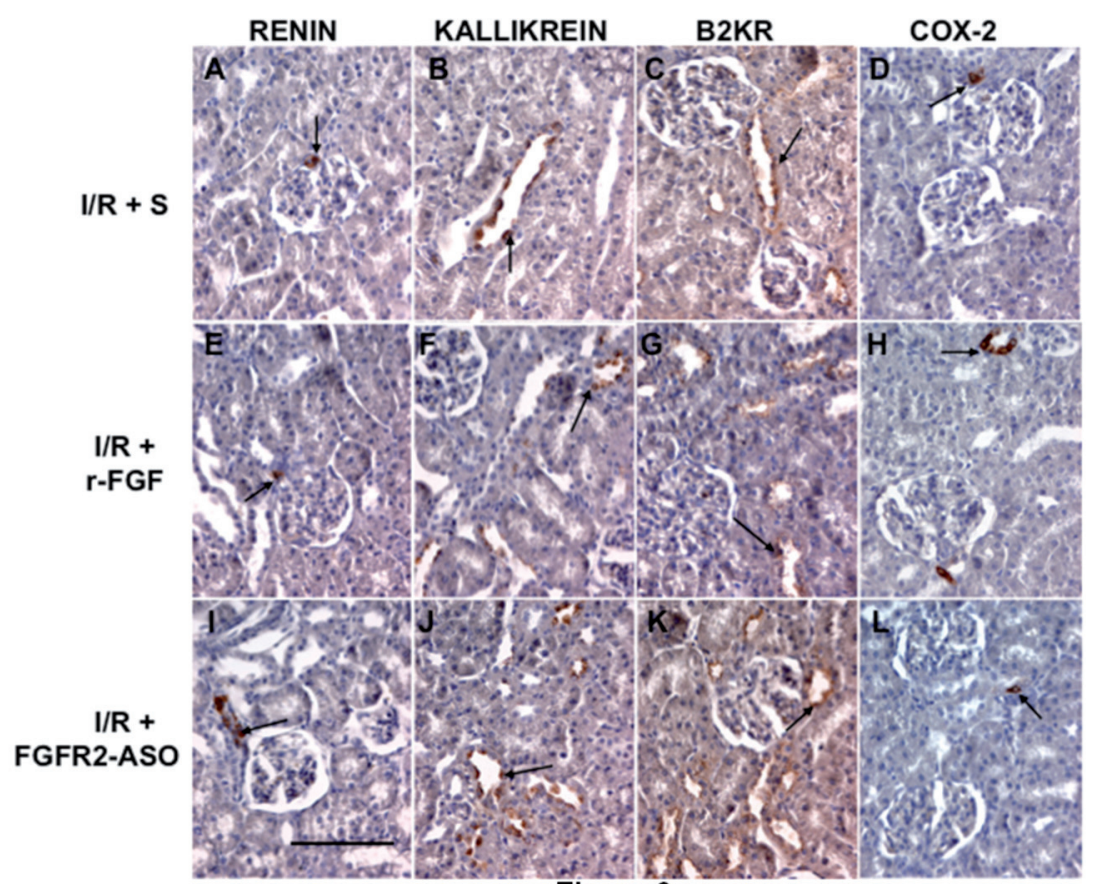

Figure 6: Immunolocalization of vasoactive proteins in I/R-induced ARF . Staining for renin (A,E \& I), kallikrein (B,F \& J), B2KR (C,G \& $\mathbf{K})$ and COX-2 (D,H \& L) was evaluated 48 hours after ischemia in kidneys injected with S (A-D), r-FGF (E-H) and FGFR2-ASO (I-L) ( $\mathrm{n}=7$ for each group). Scale bar $=100 \mu \mathrm{m}$. The arrows indicate representative immunostained (brown) areas. 
elicited in the protective response to $\mathrm{I} / \mathrm{R}$ damage, and that this response is not necessary or is anticipated in the presence of FGF-2.

Recent studies have shown that nitric oxide (NO) generated by iNOS is involved in many pathological states (including renal I/R), contributing to oxidative damage of critical cellular macromolecules (Chatterjee et al., 2002; Viñas et al., 2006). In addition, the increase in $\mathrm{HO}-1$, together with an increase in iNOS, the former producing $\mathrm{CO}$ and the latter producing $\mathrm{NO}$, could contribute to the production of $\mathrm{NO}$ in a regulated and beneficial form (Lee and Yen, 2009). In this study, we have shown that FGF-2 is involved in the suppression of iNOS and $\mathrm{HO}-1$ induction, suggesting that additional production of $\mathrm{NO}$ and $\mathrm{CO}$ is not needed to preserve renal function in the presence of this growth factor or, as previously speculated for HO-1 and EPO, the effects on iNOS regulation were anticipated at least 24 hours when r-FGF was administered.

We have also analyzed the FGF effect on some proteins from renal vasoactive systems that have been involved in renal development, and that could participate in the recovery of renal damage. As mentioned previously, the activity of the KKS is important for normal kidney development (Shen and El-Dahr, 2006). Kallikrein cleaves kininogen to produce bradykinin (BK), which binds to its receptor B2KR, activating intracellular signaling (Velarde et al., 1995). B2KR is constitutively expressed in renal tissues, and has been associated with the differentiation of the distal nephron and epithelial cells derived from embryonic stem cells (El-Dahr, 2004). When BK concentration increases, the receptor is down-regulated by internalization, followed by degradation (Velarde et al., 1995). The up-regulation of B2KR observed in saline treated kidneys after 24 hours of I/R could be explained by a decrease in bradykinin, caused by the reduction of kallikrein, observed at that same time period. In addition, it has been observed that the B2KR is induced by hypoxia in endothelial cells (Liesmaa et al., 2009), which is also consistent with the high levels of B2KR observed $24 \mathrm{~h}$ after I/R. The negative feedback of BK toward its receptor could explain the increase in kallikrein and the reduction of the receptor observed 48 hours after I/R. Recent reports have shown that $\mathrm{B} 2 \mathrm{KR}$ expression and BK secretion decrease during in vitro differentiation (Martins et al., 2008), suggesting an additional regulatory mechanism. The participation of FGF in tissue differentiation and the observations of Martins et al., could explain the reduction of kallikrein and the B2KR in the presence of r-FGF at 96 hours after I/R, as well as the opposite effect with FGFR2-ASO observed in the present study.

The effect of COX-2 on renal damage is controversial; while Matsuyama et al. (2005) proposed that COX-2 might induce renal tissue damage triggered by $I / R$, other authors have suggested a role for COX-2 in regeneration (Feitoza et al., 2005). Several studies have shown COX-2 participation in nephron development (Vio et al., 1999) and tissue repair (Eligini et al., 2009; Brzozowski et al., 2000; Mizuno et al., 1997; Hamamoto et al., 2009; Bondesen et al., 2004; Reuter et al., 1996; Leahy et al., 2002). In addition, a beneficial effect of COX-2-derived mediators has been reported; examples are lipoxin in acute lung injury (Fukunaga et al., 2005) and prostaglandin E2 in corneal endothelial injury (Jumblatt and Willer, 1996). Furthermore, an inhibitory effect on apoptosis has been described in renal glomerular mesangial cells (Ishaque et al., 2003).

The results obtained in the present study might be explained by the effects of COX-2 derivatives on proteins induced by renal damage. In this sense, the regulation of COX2 expression acquires great importance. Our observations indicate that COX-2 has an opposite regulation from those of the other studied proteins. We postulate that COX-2 has a similar effect to the one reported previously in kidney tubular cells, in terms of its involvement in repairing tissue damage. However, this COX-2 effect might only be observed when renal tubules are preserved and COX-2 can be induced as occurs in the presence of r-FGF. In contrast, when tissue damage is high, as observed in $\mathrm{I} / \mathrm{R}+\mathrm{S}$, the induction of COX-2 would not be possible. Additionally, recent publications have shown a direct association between COX-2 and FGF-2 (Baguma-Nibasheka et al., 2007), and COX-2 mRNA has been shown to increase in response to FGF-2 administration in retinal epithelial cells, (Ershov and Basan, 1999). A decrease in COX-2 and an increase in HO-1 activity have also been observed in endothelial cells (Morimoto et al., 2001; Li et al., 2003), suggesting that the heme-hemoxygenase system could be a negative regulator for COX-2 expression.

In summary, it is obvious that this study has some limitations due to two facts, namely that it is an in vivo study and, as such, it is hard to isolate one single effect, and that most of the experiments are not quantitative, so they only reflect a relationship between the compared proteins. However, despite such limitations, it is possible to postulate that FGF could be acting as a master regulator in I/R. In this sense, we suggest a model in which iNOS, HO-1, EPO, Renin, Kallikrein, B2KR are initially stimulated by FGF to induce cell proliferation and tissue regeneration. The continuous presence of FGF-2 could act as negative feedback to the abovementioned proteins to end a phase, and as a positive stimulus to COX-2 that, after the reduction of HO-1, could increase and act on the following phase of differentiation. Consequently, further studies are needed to evaluate this new model. Nevertheless, this study opens a new perspective for the use of FGF-2 in future research for kidney damage and regeneration.

\section{ACKNOWLEDGEMENTS}

The authors thank Mrs. Dr. Elisa Marusic for critical readings of this manuscript, and Mrs. Maria Alcoholado and Mr. Cesar Vergara for technical assistance in tissue processing. This work was supported by Fondecyt Grant N ${ }^{\circ}$ s 11075029 (SV), 1080590 (CPV), FAI 002-08 (SV, CPV), Anillo Act71 and Proyecto Puente 2/2011 (VV) and the Programa de Financiamiento Basal PFB 12-2007 (CPV).

\section{REFERENCES}

AKIBA Y, NAKAMURA M, ODA M, KIMURA H, MIURA S, TSUCHIYA M, ISHII H (1997) Basic fibroblast growth factor increases constitutive nitric oxide synthase during healing of rat gastric ulcers. J Clin Gastroenterol 25:S122-S128.

ASHLEY RA, DUBUQUE SH, DVORAK B, WOODWARD SS, WILLIAMS SK, KLING PJ (2002) Erythropoietin stimulates vasculogenesis in neonatal rat mesenteric microvascular endothelial cells. Pediatr Res 51:472-478.

BAGUMA-NIBASHEKA M, BARCLAY C, LI AW, GELDENHUYS L, PORTER GA, BLAY J, CASSON AG, MURPHY PR (2007) Selective cyclooxygenase-2 inhibition suppresses basic fibroblast growth factor expression in human esophageal adenocarcinoma. Mol Carcinog 46:971-980.

BASILE DP, FREDRICH K, ALAUSA M, VIO CP, LIANG M, RIEDER MR, GREENE AS, COWLEY AW JR (2005) Identification of persistently 
altered gene expression in the kidney after functional recovery from ischemic acute renal failure. Am J Physiol Renal Physiol 288:F953-F963.

BONDESEN BA, MILLS ST, KEGLEY KM, PAVLATH GK (2004) The COX-2 pathway is essential during early stages of skeletal muscle regeneration. Am J Physiol Cell Physiol 287:C475-C483.

BRADEN GL, O'SHEA MH, MULHERN JG, AND GERMAIN MJ (2004) Acute renal failure and hyperkalaemia associated with cyclooxygenase-2 inhibitors. Nephrol Dial Transplant 19:1149-1153.

BRZOZOWSKI T, KONTUREK PC, KONTUREK SJ, PAJDO R, SCHUPPAN D, DROZDOWICZ D, PTAK A, PAWLIK M, NAKAMURA T, HAHN EG (2000) Involvement of cyclooxygenase (COX)-2 products in acceleration of ulcer healing by gastrin and hepatocyte growth factor. $J$ Physiol Pharmacol 51:751-773.

BUNN HF, AND POYTON RO (1996) Oxygen sensing and molecular adaptation to hypoxia. Physiol Rev 76:839-885.

CANCILLA B, DAVIES A, CAUCHI JA, RISBRIDGER GP, BERTRAM JF (2001). Fibroblast growth factor receptors and their ligands in the adult rat kidney. Kidney Int 60:147-155.

CARSTENS RP, WAGNER EJ, GARCÍA-BLANCO MA (2000) An intronic splicing silencer causes skipping of the IIIb exon of fibroblast growth factor receptor 2 through involvement of polypyrimidine tract binding protein. Mol Cell Biol 20:7388-7400.

CHATTERJEE PK, PATEL NS, KVALE EO, CUZZOCREA S, BROWN PA, STEWART KN, MOTA-FILIPE H, THIEMERMANN C (2002) Inhibition of inducible nitric oxide synthase reduces renal ischemia/reperfusion injury. Kidney Int 61:862-871.

CUEVAS P, MARTÍNEZ-COSO V, FU X, ORTE L, REIMERS D, GIMÉNEZGALLEGO G, FORSSMANN WG, SÁENZ DE TEJADA I (1999) Fibroblast growth factor protects the kidney against ischemiareperfusion injury. Eur J Med Res 4:403-410.

EL-DAHR SS (2004) Spatial expression of the kallikrein-kinin system during nephrogenesis. Histol Histopathol 19:1301-1310.

ELIGINI S, ARENAZ I, BARBIERI SS, FALERI ML, CRISCI M, TREMOLI E, COLLI S (2009) Cyclooxygenase-2 mediates hydrogen peroxideinduced wound repair in human endothelial cells. Free Radic Biol Med 46:1428-1436

ERSHOV AV, BAZAN NG (1999) Induction of cyclooxygenase-2 gene expression in retinal pigment epithelium cells by photoreceptor rod outer segment phagocytosis and growth factors. I Neurosci Res 58:254-261.

ESSON ML, SCHRIER RW (2002) Diagnosis and treatment of acute tubular necrosis. Ann Intern Med 137:744-752.

FEITOZA CQ, CÂMARA NO, PINHEIRO HS, GONÇALVES GM, CENEDEZE MA, PACHECO-SILVA A, SANTOS OF (2005) Cyclooxygenase 1 and/or 2 blockade ameliorates the renal tissue damage triggered by ischemia and reperfusion injury. Int Immunopharmacol 5:79-84.

FRIESEL R, MACIAG T (1999) Fibroblast growth factor prototype release and fibroblast growth factor receptor signaling. Thromb Haemost. 82:748-754

FUKUNAGA K, KOHLI P, BONNANS C, FREDENBURGH LE, LEVY BD (2005) Cyclooxygenase 2 plays a pivotal role in the resolution of acute lung injury. J Immunol 174:5033-5039.

HAMAMOTO T, YABUKI A, YAMATO O, FUJIKI M, MISUMI K, MATSUMOTO M (2009) Immunohistochemical analysis of cyclooxygenase-2 induction during wound healing in dog skin. Res Vet Sci 87:349-354.

ISHAQUE A, DUNN MJ, SOROKIN A (2003) Cyclooxygenase-2 inhibits tumor necrosis factor alpha-mediated apoptosis in renal glomerular mesangial cells. J Biol Chem 278:10629-10640.

JUMBLATT MM, WILLER SS (1996) Corneal endothelial repair. Regulation of prostaglandin E2 synthesis. Invest Ophthalmol Vis Sci 37:1294-1301.

KIRKBY KA, ADIN CA (2006) Products of heme oxygenase and their potential therapeutic applications. Am J Physiol Renal Physiol 290:F563-F571.

KREJA L, THOMA S, SELIG C, LAMPING C, ZIEGLER BL, NOTHDURFT W (1993) The effect of recombinant human stem cell factor and basic fibroblast growth factor on the in vitro radiosensitivity of CD34+ hematopoietic progenitors from human umbilical cord blood. Exp Hematol 21:1436-1441

LEAHY KM, ORNBERG RL, WANG Y, ZWEIFEL BS, KOKI AT, MASFERRER JL (2002) Cyclooxygenase-2 inhibition by celecoxib reduces proliferation and induces apoptosis in angiogenic endothelial cells in vivo. Cancer Res 62: 625-631.

LEE PJ, JIANG BH, CHIN BY, IYER NV, ALAM J, SEMENZA GL, CHOI AM (1997) Hypoxia-inducible factor-1 mediates transcriptional activation of the heme oxygenase-1 gene in response to hypoxia. J Biol Chem 272: $5375-5381$.

LEE CY, YEN MH (2009) Nitric oxide and carbon monoxide, collaborative and competitive regulators of hypertension. Chang Gung Med J. 32: 12-21.

LEÓN CG, MARCHETTI J, VIO CP (2001) Renal cyclooxygenase-2: evidence for recruitment of thick ascending limb of henle cells in microdissected nephron segments. Hipertension 38:630-634

LI VOLTI G, SETA F, SCHWARTZMAN ML, NASJLETTI A, ABRAHAM NG (2003) Heme oxygenase attenuates angiotensin II-mediated increase in cyclooxygenase-2 activity in human femoral endothelial cells. Hypertension 41:715-719.

LIESMAA I, LESKINEN HK, KOKKONEN JO, RUSKOAHO H, KOVANEN PT, LINDSTEDT KA (2009) Hypoxia-induced expression of bradykinin type-2 receptors in endothelial cells triggers NO production, cell migration, and angiogenesis. J Cell Physiol 221:359-366.MARTINS AH, ALVES JM, TRUJILLO CA, SCHWINDT TT, BARNABÉ GF, MOTTA FL, GUIMARAES AO, CASARINI DE, MELLO LE, PESQUERO JB, ULRICH H (2008) Kinin-B2 receptor expression and activity during differentiation of embryonic rat neurospheres. Cytometry A 73:361-368.

MATSUYAMA M, YOSHIMURA R, HASE T, KAWAHITO Y, SANO $\mathrm{H}_{\text {, }}$ NAKATANI T (2005) Study of cyclooxygenase-2 in renal ischemiareperfusion injury. Transplant Proc 37:370-372.

MEHTA R (2003) Outcomes research in acute renal failure. Semin Nephrol 23:283-294.

MELILLO G, TAYLOR LS, BROOKS A, MUSSO T, COX GW, VARESIO L (1997) Functional requirement of the hypoxia-responsive element in the activation of the inducible nitric oxide synthase promoter by the iron chelator desferrioxamine. J Biol Chem; 272:12236-12243.

MIZUNO H, SAKAMOTO C, MATSUDA K, WADA K, UCHIDA T, NOGUCHI H, AKAMATSU T, KASUGA M (1997) Induction of cyclooxygenase 2 in gastric mucosal lesions and its inhibition by the specific antagonist delays healing in mice. Gastroenterology 112:387-397.

MOLITORIS BA, SUTTON TA (2004) Endothelial injury and dysfunction: role in the extension phase of acute renal failure. Kidney Int 66:496-499.

MORIMOTO K, OHTA K, YACHIE A, YANG Y, SHIMIZU M, GOTO C, TOMA T, KASAHARA Y, YOKOYAMA H, MIYATA T, SEKI H, KOIZUMI S (2001) Cytoprotective role of heme oxygenase (HO)-1 in human kidney with various renal diseases. Kidney Int 60:1858-1860.

NEUVIANS TP, SCHAMS D, BERISHA B, PFAFFL MW (2004) Involvement of pro-inflammatory cytokines, mediators of inflammation, and basic fibroblast growth factor in prostaglandin F2alpha-induced luteolysis in bovine corpus luteum. Biol Reprod 70:473-480.

NOIRI E, NAKAO A, UCHIDA K, TSUKAHARA H, OHNO M, FUITA T, BRODSKY S, GOLIGORSKY MS (2001) Oxidative and nitrosative stress in acute renal ischemia. Am J Physiol Renal Physiol 281:F948-F957.

PERANTONI AO, DOVE LF, KARAVANOVA I (1995) Basic fibroblast growth factor can mediate the early inductive events in renal development. Proc Natl Acad Sci USA 92:4696-4700.

REUTER BK, ASFAHA S, BURET A, SHARKEY KA, WALLACE JL (1996) Exacerbation of inflammation-associated colonic injury in rat through inhibition of cyclooxygenase-2. J Clin Invest 98:2076-2085.

SCHMAIER AH (2003) The kallikrein-kinin and the renin-angiotensin systems have a multilayered interaction. Am J Physiol Regul Integr Comp Physiol 285:R1-R13.

SCHMERER M, TORREGROZA I, PASCAL A, UMBHAUER M, EVANS T (2006) STAT5 ACTS AS A REPRESSOR TO REGULATE EARLY EMBRYONIC ERYTHROPOIESIS. BLOOD 108:2989-2997.

SCHRIER RW, WANG W, POOLE B, MITRA A (2004) Acute renal failure: definitions, diagnosis, pathogenesis, and therapy. J Clin Invest 114:5-14.

SEIBERT K, ZHANG Y, LEAHY K, HAUSER S, MASFERRER J, PERKINS W, LEE L, ISAKSON P (1994) PHARMACOLOGICAL AND BIOCHEMICAL DEMONSTRATION OF THE ROLE OF CYCLOOXYGENASE 2 IN INFLAMMATION AND PAIN. PROC NATL ACAD SCI USA 91:12013-12017.

SHARPLES EJ, PATEL N, BROWN P, STEWART K, MOTA-PHILIPE H, SHEAFF M, KIESWICH J, ALLEN D, HARWOOD S, RAFTERY M, THIEMERMANN C, YAQOOB MM (2004) Erythropoietin protects the kidney against the injury and dysfunction caused by ischemiareperfusion. J Am Soc Nephrol 15:2240-2241.

SHARPLES EJ, THIEMERMANN C, YAQOOB MM (2005) Mechanism of disease: Cell death in acute renal failure and emerging evidence for a protective role of erythropoietin. Nat Clin Pract Nephrol 1:87-97.

SHEN B, EL-DAHR SS (2006) Cross-talk of the renin-angiotensin and kallikrein-kinin systems. Biol Chem 387:145-150.

SHIMIZU H, TAKAHASHI T, SUZUKI T, YAMASAKI A, FUJIWARA T, ODAKA Y, HIRAKAWA M, FUJITA H, AKAGI R (2000) Protective 
effect of heme oxygenase induction in ischemic acute renal failure. Crit Care Med 28:809-817.

SUTTON TA, FISHER CJ, MOLITORIS BA (2002) Microvascular endothelial injury and dysfunction during ischemic acute renal failure. Kidney Int 62:1539-1549.

TAYLOR CT, COLGAN SP (1999) Therapeutic targets for hypoxia-elicited pathways. Pharm Res 16:1498-1505.

UNGER EF, GONCALVES L, EPSTEIN SE, CHEW EY, TRAPNELL CB, CANNON RO 3RD, QUYYUMI AA (2000) Effects of a single intracoronary injection of basic fibroblast growth factor in stable angina pectoris. Am J Cardiol 85:1414-1419.

VELARDE V, HUMPHREYS J, FIGUEROA CD, VIO CP (1995) Postnatal maturation of tissue kallikrein-producing cells (connecting tubule cells) in the rat kidney: a morphometric and immunohistochemical study. Anat Embryol 192:407-414.

VILLANUEVA S, CÉSPEDES C, GONZÁlEZ A, VIO CP (2006a) bFGF induces an earlier expression of nephrogenic proteins after ischemic acute renal failure. Am J Physiol Regul Integr Comp Physiol 291:R1677-R1687.

VILLANUEVA S, CÉSPEDES C, VIO CP (2006b) Ischemic acute renal failure induces the expression of a wide range of nephrogenic proteins. Am J Physiol Regul Integr Comp Physiol 290:R861-R870.
VILLANUEVA S, CÉSPEDES C, GONZÁLEZ AA, VIO CP, VELARDE V (2007) Effect of ischemic acute renal damage on the expression of COX-2 and oxidative stress-related elements in rat kidney. Am J Physiol Renal Physiol 292:F1364-F1371.

VILLANUEVA S, CÉSPEDES C, GONZÁLEZ AA, ROESSLER E, VIO CP (2008) Inhibition of bFGF-receptor type 2 increases kidney damage and suppresses nephrogenic protein after ischemic acute renal failure. Am J Physiol Regul Integr Comp Physiol 294:R819-R828.

VIÑAS JL, SOLA A, GENESCA M, ALFARO V, PI F, HOTTER G (2006) NO and NOS isoforms in the development of apoptosis in renal ischemia/ reperfusion. Free Radic Biol Med 40:992-1003.

VIO CP, CÉSPEDES C, GALLARDO P, MASFERRER JL (1997) RENAL IDENTIFICATION OF CYCLOOXYGENASE-2 IN A SUBSET OF THICK ASCENDING LIMB CELLS. HYPERTENSION 30: 687-692.

VIO CP, BALESTRINI C, RECABARREN M, CÉSPEDES C (1999) Postnatal development of cyclooxygenase-2 in the rat kidney. Immunopharmacology 44:205-210.

VIO CP, AN SH, CÉSPEDES C, MCGIFF J, FERRERI N (2001) Induction of cyclooxygenase- 2 in thick ascending limb cells by adrenalectomy. $J$ Am Soc Nephrol 12:649-658.

YANG L, QUAN S, NASJLETTI A, LANIADO-SCHWARTZMAN M, ABRAHAM NG (2004) Heme oxygenase-1 gene expression modulates angiotensin II-induced increase in blood pressure. Hypertension 43:1221-1226. 